(and

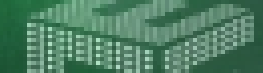

\title{
Cloacal microbiota of barn swallows from Northern Italy
}

Federica Musitelli, Roberto Ambrosini, Diego Rubolini, Nicola Saino, Andrea Franzetti \& Isabella Gandolfi

To cite this article: Federica Musitelli, Roberto Ambrosini, Diego Rubolini, Nicola Saino, Andrea Franzetti \& Isabella Gandolfi (2017): Cloacal microbiota of barn swallows from Northern Italy, Ethology Ecology \& Evolution, DOI: 10.1080/03949370.2017.1388294

To link to this article: https://doi.org/10.1080/03949370.2017.1388294

View supplementary material $₫$

曲 Published online: 30 Oct 2017.

Submit your article to this journal $₫$

山 Article views: 69

Q View related articles ¿

View Crossmark data \lceil 


\title{
Short communication
}

\section{Cloacal microbiota of barn swallows from Northern Italy}

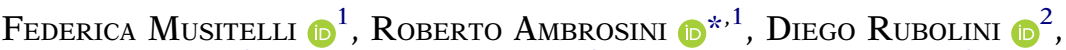 \\ Nicola Saino (iD ${ }^{2}$, Andrea Franzetti (iD ${ }^{1}$ and Isabella Gandolfi ${ }^{1}$ \\ ${ }^{1}$ Department of Earth and Environmental Sciences (DISAT), University of Milano \\ Bicocca, Piazza della Scienza 1, Milan 20126, Italy \\ ${ }^{2}$ Department of Environmental Science and Policy, University of Milan, Via Celoria 26, \\ Milan 20133, Italy
}

Received 12 April 2017, accepted 14 September 2017

\begin{abstract}
Bird gut microbiota shows large variation among geographical populations of the same species - probably because, differently from mammals, gut microbiota of birds is largely affected by extrinsic factors such as diet and environmental conditions. We analysed the cloacal microbiota (CM) of 12 barn swallows (Hirundo rustica) from a colony in Northern Italy by high-throughput DNA sequencing of the 16S rRNA gene. The CMs, dominated by bacteria of the phyla Proteobacteria, Actinobacteria, Firmicutes and Bacteroidetes, did not significantly differ between adult females, adult males and fledglings. This first description of barn swallow CM in Italy, together with two previous studies from Europe, suggests that CMs of geographically different barn swallow populations are dominated by bacteria belonging to the same phyla but different genera. The intra-colony similarity of the CMs may be due to the exposure of individuals to the same local environmental conditions while on their breeding grounds.
\end{abstract}

KEY WORDS: barn swallow, gut microbiota, Hirundo rustica, Illumina sequencing, microbiome.

\section{INTRODUCTION}

Recent studies have demonstrated that the gut microbiota can influence the physiology and behaviour of vertebrate species (Fraune \& Bosch 2010) by affecting host physiology, improving nutrient assimilation, promoting detoxification and supporting immunological responses with consequences on host growth and survival (Mead 1997; Fraune \& Bosch 2010). Moreover, the composition of the gut microbiota

"Corresponding author: Roberto Ambrosini, Dipartimento di Scienze dell'Ambiente e della Terra, Università degli Studi di Milano Bicocca, Piazza della Scienza 1, 20126 Milano, Italy (E-mail: roberto. ambrosini@unimib.it). 
seems to influence host behaviour, particularly by influencing mate choice and reproduction (Kokko et al. 2002; Sharon et al. 2010). Alteration of gut microbiota may also exert negative effects, determining physiological disorders of the host, increasing its susceptibility to pathogens, and ultimately reducing its fitness (Muegge et al. 2011; Bik et al. 2016).

Little is currently known about the factors that shape the structure of intestinal bacterial communities. A recent review by Colston and Jackson (2016) highlighted that the host genetics and phylogeny influence the structure of bacterial communities in the gut of mammals, fishes and reptiles. In contrast, diet and geography seem the main factors affecting avian gut microbiome (Waite \& Taylor 2014; see Colston \& Jackson 2016 and references therein). Studies on birds also suggest that nestlings acquire their microbiota from the nest environment immediately after hatching or through the bolus regurgitated by parents, providing an example of vertical transmission of bacteria through generations (Lucas \& Heeb 2005; Van Dongen et al. 2013). Bacteria can be transferred also between adult birds during copulation (White et al. 2010; Kreisinger et al. 2015). This horizontal transfer of gut bacteria is favoured by the anatomy of the reproductive system of birds. Indeed, the avian cloaca serves both for defecation and for gamete transfer, creating the condition for sexual transmission of intestinal bacteria (Sheldon 1993; Lombardo 1998; White et al. 2010). These features suggest that birds could be a valuable model for investigating the processes that shape the bacterial communities of the intestinal trait (White et al. 2010).

We studied the cloacal microbiota (CM) of 12 barn swallows (Hirundo rustica) from a colony in Northern Italy during the breeding season 2015. To date, only two published studies from the Czech Republic have investigated barn swallow CM (Kreisinger et al. 2015, 2017). In light of the large variability in the microbiota of bird populations from different geographical areas (Colston \& Jackson 2016), our aim was to provide a description of the $\mathrm{CM}$ of a geographically different population. In addition, we investigated whether the structure of the bacterial communities of the CM differed among age classes (adults or fledglings) and sexes (adult males or adult females). CM is a subset of intestinal microbiota, and it is directly communicating with both the urogenital tract and the external environment. This makes it more susceptible to horizontal transfer of bacteria between individuals. Moreover, CM sampling is easily feasible by swabs (see Methods), while the study of bacterial communities of more internal tracts of the gastrointestinal apparatus would require the sacrifice of some individuals, which is ethically not acceptable for a protected species like the barn swallow.

\section{METHODS}

Study species and field procedures

The barn swallow is a small, aerially insectivorous, long-distance migratory bird that breeds semi-colonially mostly in rural buildings (Turner 2006). Socially monogamous breeding pairs have one to three broods of one to seven nestlings per breeding season. Offspring are altricial and are attended by both parents for approximately 20 days. Adult barn swallows can be easily sexed during the breeding season from presence (females) or absence (males) of brood patch (Møller 1994; Turner 2006), while fledglings are monomorphic and cannot be sexed in the field until their first moult (Møller 1994; Turner 2006).

We sampled CM of four adult males, five adult females and three fledglings captured by mist nets in a breeding colony (Milan, Italy; $45^{\circ} 28^{\prime} 48.8^{\prime \prime} \mathrm{N}, 9^{\circ} 06^{\prime} 05.3^{\prime \prime} \mathrm{E}$ ) on 24 July 2015 . CM samples 
were collected using sterile DNA-free microbiological nylon swabs (minitip FLOQSwabs 516CS01, COPAN, Brescia, Italy) inserted $\sim 10 \mathrm{~mm}$ inside the cloaca for $\sim 20 \mathrm{sec}$ and gently twisted by $\sim$ $360^{\circ}$. All samples were kept at $+4{ }^{\circ} \mathrm{C}$ while in the field and brought to the lab within $5 \mathrm{hr}$ from collection, where they were stored at $-20^{\circ} \mathrm{C}$ until processing. Six samples were stored in $2 \mathrm{~mL}$ aseptic microcentrifuge tubes (Eppendorf AG, Germany), while the others were stored in $1 \mathrm{~mL}$ of eSwab $^{\mathrm{TM}}$ preservative (484CE eSwab ${ }^{\mathrm{TM}}$, COPAN, Brescia, Italy).

The study was carried out under permission of the local authority (Regione Lombardia, DGR 190 issued on 19 January 2015) responsible for authorizing animal studies in the wild. The owner of the riding school where we collected samples gave us the permission to conduct this work.

\section{DNA extraction and sequencing}

Total DNA was extracted from the swabs with FastDNA® Spin kit for Soil (MP Biomedicals, Solon, OH, USA). Dry swabs were directly inserted into the Lysing Matrix E tube. Microtubes containing the swabs stored in $\mathrm{eSwab}^{\mathrm{TM}}$ preservative were vortexed, and the whole content $(\sim 1 \mathrm{~mL})$ of each microtube was transferred to a Lysing Matrix E tube while adding $500 \mu \mathrm{L}$ of sodium phosphate buffer. Further steps of DNA extraction were performed according to manufacturer's instructions. The V5-V6 hypervariable regions of the bacterial 16S rRNA gene were PCR-amplified by preparing $2 \times 75 \mu \mathrm{L}$ volume PCR reactions for each sample and including a 6-bp barcode at the $5^{\prime}$ end of each primer (Huber et al. 2007; Wang \& Qian 2009) to allow sample pooling and sequence sorting. Amplicons bearing different barcode pairs were pooled together to build libraries. Further library preparation with the addition of standard Nextera indexes (Illumina, Inc., San Diego, CA, USA; see also Gandolfi et al. 2017 for further details) and sequencing were carried out at Parco Tecnologico Padano (Lodi, Italy).

Reads from sequencing were demultiplexed according to the indices and the Uparse pipeline was used for the following elaborations (Edgar 2013). Forward and reverse reads were merged with perfect overlapping and quality filtered with default parameters. Chimera checking was run on pooled unique reads before the OTU clustering, and allowed removing $6764(10.5 \%)$ suspected chimera sequences. Singleton sequences (i.e. sequences appearing only once in the whole data set) were also removed. Operational taxonomic units (OTUs) were defined on the whole data set clustering the sequences at $97 \%$ of similarity and defining a representative sequence for each cluster. Abundance of each OTU was estimated by mapping the sequences of each sample against the representative sequence of each OTU at $97 \%$ of similarity. Taxonomic classification of the OTU representative sequences was obtained by RDP classifier (Wang et al. 2007).

Sequences were deposited to EBI-ENA database with the accession numbers ERS183546172. Full datasets used in the present analyses are included in the Supplemental Material available online.

\section{Statistical analyses}

Alpha diversity. The number of sequences was used as an estimate of abundance of each OTU in a sample. We estimated the total OTU richness of each CM by the Chao1 index (Chao \& Shen 2003) because this index estimates the total OTU richness after accounting for unobserved OTUs and its values can be compared among samples with different coverage. We then compared Chao1 indices between adult males, adult females and fledglings by ANOVA followed by planned comparisons of adult males and adult females (thus excluding fledglings), and adults (i.e. pooling adult males and females) and fledglings.

Beta diversity. We compared CM structures of adult males, adult females and fledglings by redundancy analysis (RDA). Abundance of each OTU was assessed on 12,000 randomly extracted 
sequences in order to give equal coverage to each $\mathrm{CM}$. This number was slightly lower than the minimum coverage of our CMs. Also in this case, we performed planned comparisons by rerunning RDAs on adult males and adult females only, and by comparing adults and fledglings and adjusting significance according to the false discovery rate (FDR) procedure (Benjamini \& Yekutieli 2001). The Hellinger distance among CMs was used for all the analyses (De Cáceres et al. 2010; Legendre \& Legendre 2012).

Rarefaction curves showed that bacteria diversity may be underestimated with 12,000 sequences (Fig. 1). We therefore re-ran these analyses on a random subsample of 50,000 sequences for the eight samples with a larger coverage and by normalizing the coverage to 50,000 sequences for the four samples with a lower coverage. The results never changed in that all significant tests remained significant, and all non-significant ones remained non-significant (details not shown), so we report only the results obtained with 12,000 sequences.

\section{RESULTS}

\section{Composition of CM bacterial communities}

We obtained 926,729 sequences clustered in 2482 OTUs, only $109(4 \%)$ of which were present in all samples, $675(27 \%)$ in more than 50\% of the samples and $629(25 \%)$

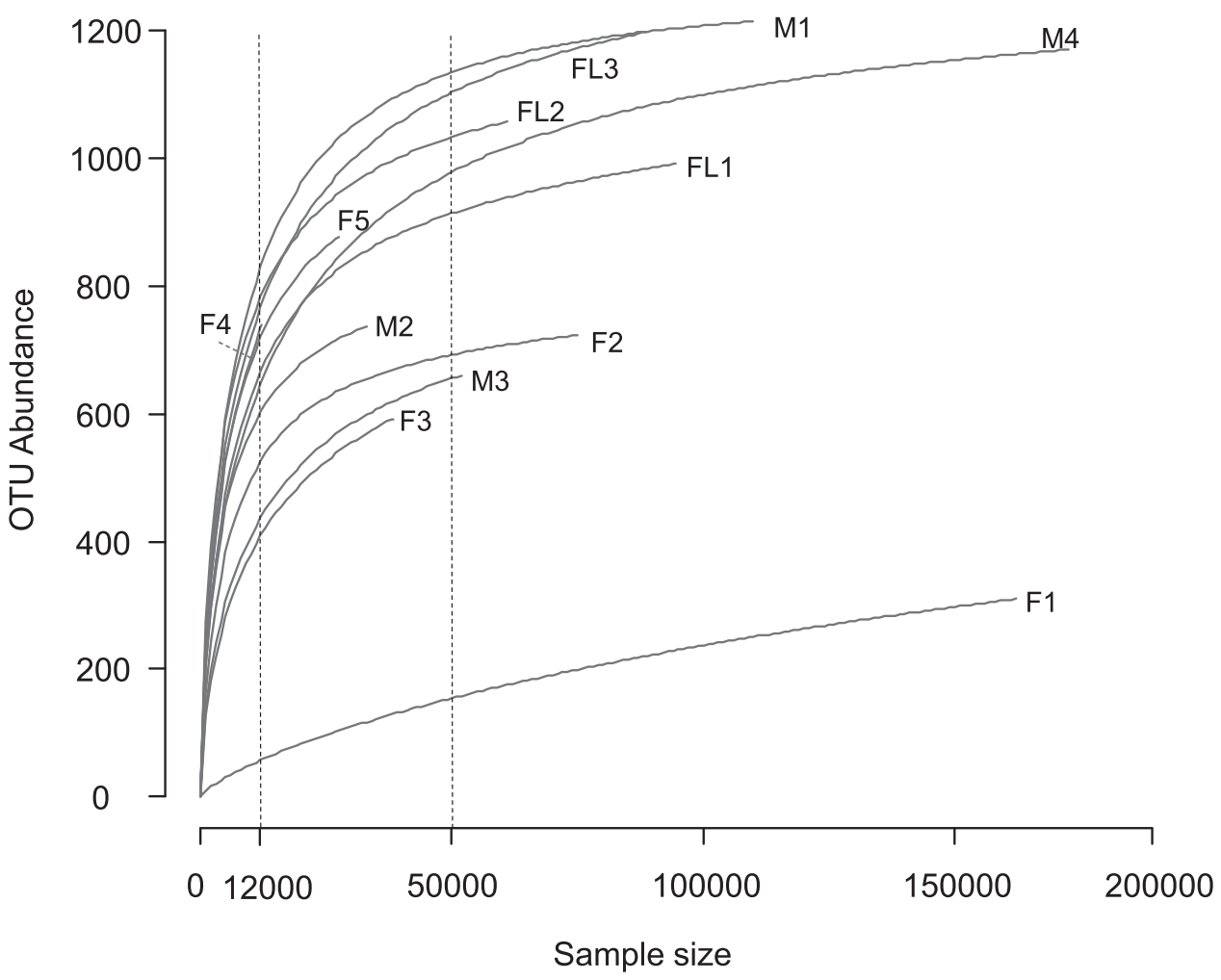

Fig. 1. - Rarefaction curves for the $12 \mathrm{CM}$ samples. The vertical dotted lines represent 12,000 and 50,000 sequences. F: adult females, M: adult males, FL: fledglings. 
were exclusive of one sample. The number of OTUs in each sample ranged between 310 and 1214. CM of one adult female (\#F1) was composed by a much smaller number of OTUs $(n=310)$ than that of the other individuals $(n \geq 592)$.

OTUs were classified in 32 phyla and 138 orders. Proteobacteria, Firmicutes, Actinobacteria and Bacteroidetes were the most abundant phyla, while Burkholderiales, Chlamydiales, Bacillales and Actinomycetales were the most abundant orders (Fig. 2). The CM of female \#F1, which showed the lowest number of OTUs, was dominated by Chlamydiales ( $86 \%$ of sequences; Fig. 2).

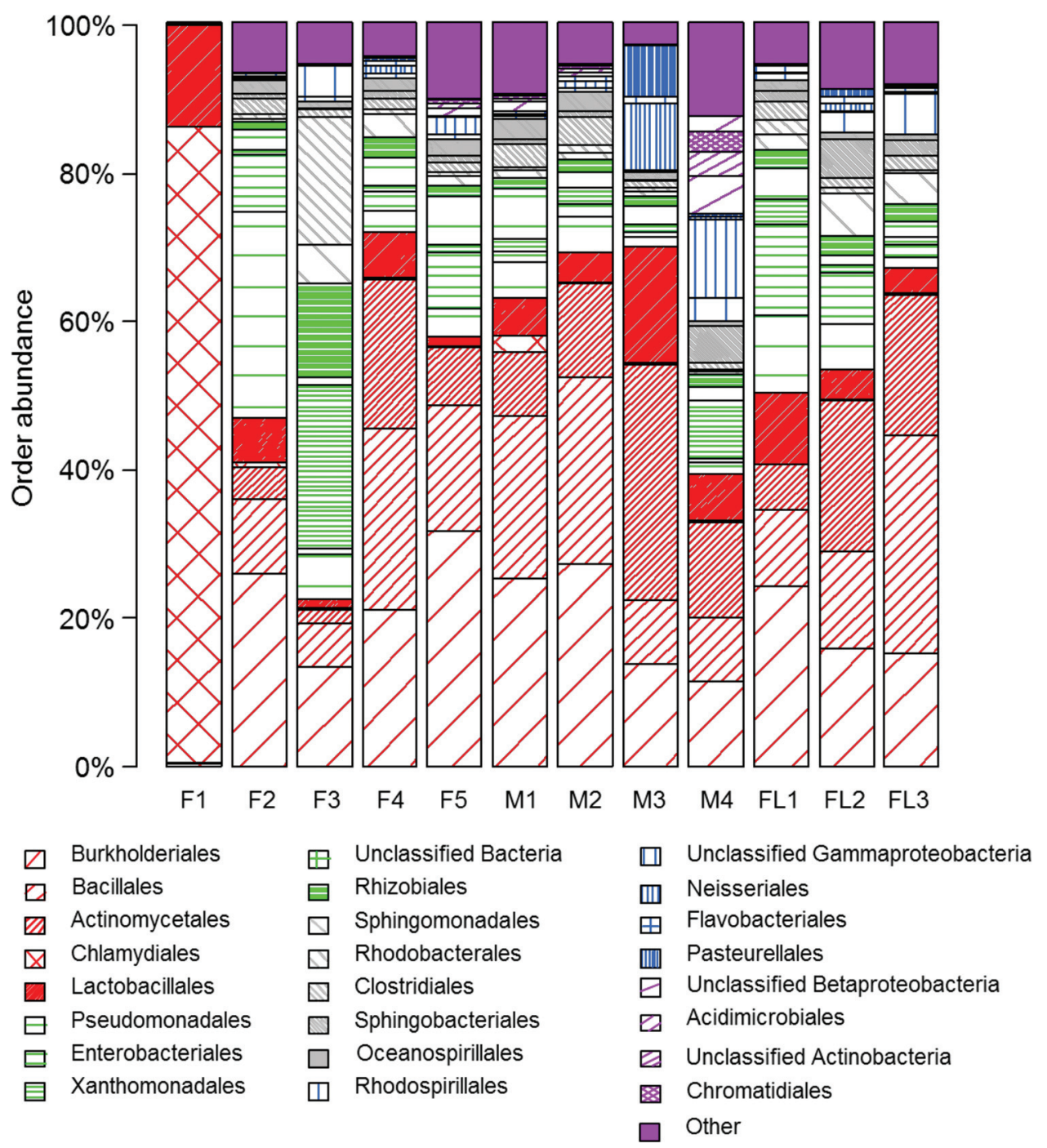

Fig. 2. - Relative OTU abundance classified at order level. F: adult females, M: adult males, FL: fledglings. 
Table 1.

Description of cloacal microbiome samples. For each sample, information about age (adult or fledgling) and sex of adults, Chao1 $( \pm$ SE) index and the number of reads before and after quality filtering is reported.

\begin{tabular}{llrrc}
\hline ID sample & Age/Sex & Chao1 index $( \pm$ SE $)$ & No. reads & No. reads after quality filtering \\
\hline F1 & Adult female & $520.34( \pm 44.85)$ & 201,604 & 170,169 \\
F2 & Adult female & $784.12( \pm 18.80)$ & 48,413 & 42,803 \\
F3 & Adult female & $753.07 \pm( \pm 33.98)$ & 128,489 & 108,879 \\
F4 & Adult female & $999.46( \pm 43.82)$ & 78,069 & 55,912 \\
F5 & Adult female & $973.89( \pm 20.22)$ & 139,840 & 102,020 \\
M1 & Adult male & $1246.58( \pm 10.47)$ & 147,751 & 128,722 \\
M2 & Adult male & $747.50( \pm 20.41)$ & 60,609 & 49,615 \\
M3 & Adult male & $1245.33( \pm 18.57)$ & 50,157 & 44,738 \\
M4 & Adult male & $788.23( \pm 13.94)$ & 224,544 & 188,257 \\
FL1 & Fledgling & $1121.49( \pm 31.19)$ & 111,052 & 80,295 \\
FL2 & Fledgling & $1128.57( \pm 17.58)$ & 21,906 & 17,383 \\
FL3 & Fledgling & $1298.53( \pm 22.22)$ & 90,813 & 68,463 \\
\hline
\end{tabular}

\section{Alpha and beta diversity of CM communities}

Values of Chao1 indices (Table 1) did not differ significantly between adult males, adult females or fledglings $\left(F_{2,9}=3.096 ; P=0.095\right)$. Planned comparisons also showed that they did not differ significantly between adult males and females $\left(t_{9}=1.419\right.$; $P=0.332)$ and between adults (males and females pooled) and fledglings $\left(t_{9}=1.963\right.$; $P=0.149$ ).

RDA indicated that the CM structure did not differ significantly between adult females, adult males or fledglings $\left(F_{2,9}=1.265 ; P=0.106\right.$; Fig. 3$)$ nor between adult males and adult females $\left(\mathrm{F}_{1,7}=0.938 ; P_{\mathrm{FDR}}=0.888\right)$ or between adults (males and females pooled $)$ and fledglings $\left(F_{1,10}=1.479 ; P_{\mathrm{FDR}}=0.306\right)$.

\section{DISCUSSION}

The phyla Proteobacteria, Actinobacteria, Firmicutes and Bacteroidetes dominated barn swallow CMs, consistently with the results on populations from the Czech Republic, which are $\sim 580 \mathrm{~km}$ far from our study area, where a high abundance of the phylum Tenericutes was also reported (Kreisinger et al. 2015, 2017). Proteobacteria and Firmicutes are common in the gastrointestinal trait of birds (Godoy-Vitorino et al. 2012; Waite et al. 2012; Waite \& Taylor 2015). A more detailed description of the bacterial community at a lower taxonomic level showed that the most abundant genera differed from those observed in previous studies: the genera Ralstonia, Pseudomonas, Aeribacillus, and Arenimonas were abundant in our samples, while they were not found in the two previous studies in the Czech Republic (Kreisinger et al. 2015, 2017). Ralstonia spp. and Pseudomonas spp. are abundant microorganisms in many matrices such as soil and water, and they have been 


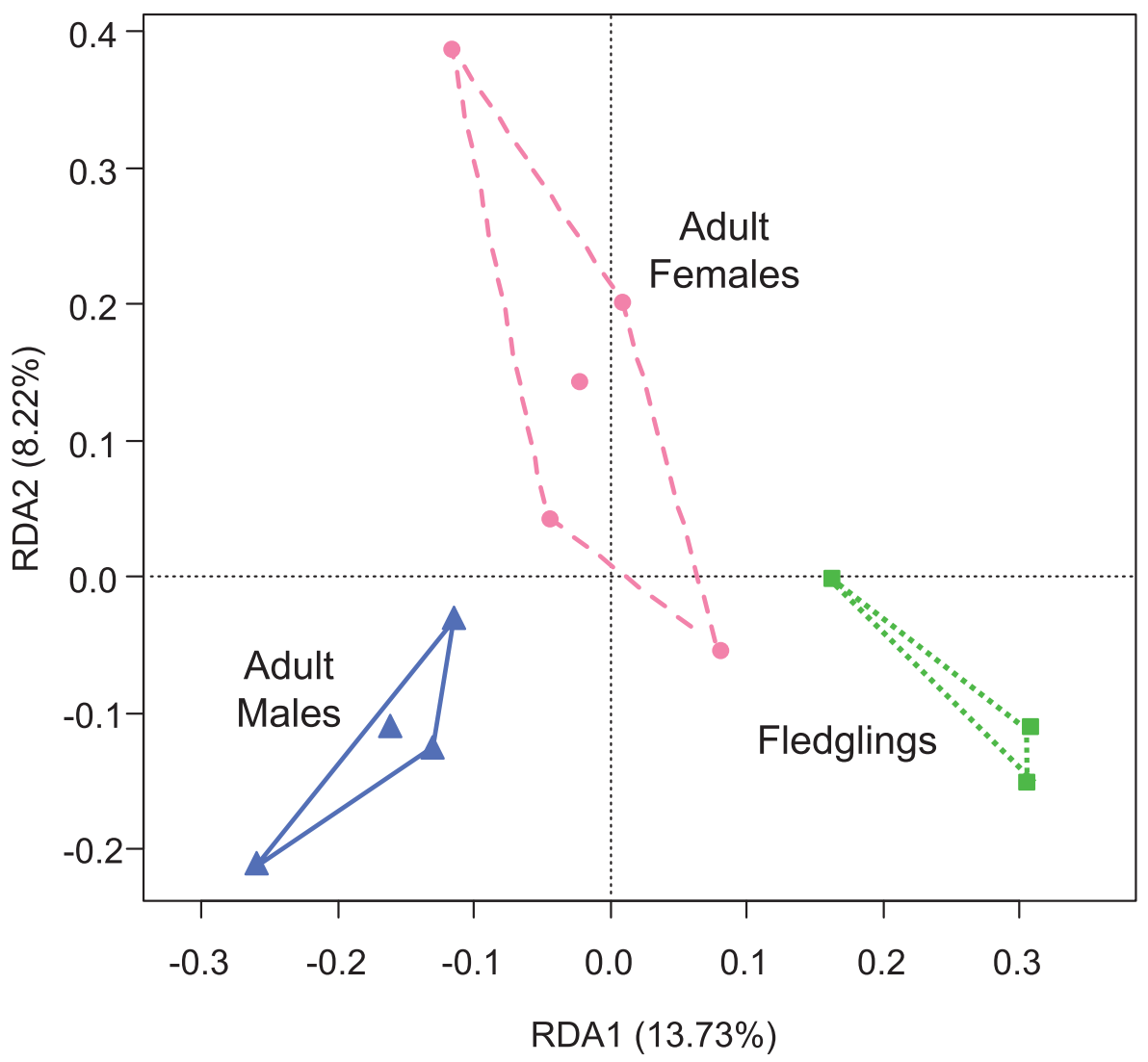

Fig. 3. - Biplot of first and second components from RDA of CM bacterial communities of 12 barn swallows. Each symbol represents the $\mathrm{CM}$ of one individual. Different symbols and colours represent sex or age classes (pink dots = adult females, blue triangles = adult males, green squares = fledglings) .

found also in association with plants and animals (Brown 2014). Aeribacillus spp. are endospore-forming thermophilic bacteria closely related to Geobacillus genus, which has been described as ubiquitous in cold environments (Filippidou et al. 2015). Arenimonas spp. are aerobic non-spore-forming bacteria whose presence has been documented in soils and sediments. Interestingly, the two studies by Kreisinger and colleagues also found some differences in the CM compositions even among barn swallow populations that bred at short distance from one another. Indeed, in one paper (Kreisinger et al. 2015), the most abundant genera were Candidatus Hamiltonella, Corynebacterium, Acinetobacter, and Comamonas, while in the other one (Kreisinger et al. 2017), the most abundant genera were Mycoplasma, Catellicoccus, Serratia, Lactobacillus, and Dysgonomonas, together with some members of the family Enterobacteriaceae that were not classified at genus level. These differences may be due, at least partly, to the different methods used in the two studies. Indeed, Kreisinger et al. (2015) collected CM by using swabs as in the present study, while Kreisinger et al. (2017) collected faeces to investigate faecal microbiota. However, faecal microbiota is generally considered as a proxy of bacterial communities of the lower intestine (Lewis et al. 2016). This difference in the methods therefore should 
not have largely affected the observed CM structure. Many genera that were abundant in the Czech populations were among the least abundant or were even absent from our samples. Only the genera Enterococcus, Staphylococcus, and Streptococcus were consistently found among the 10 most abundant genera in at least two out of the three studies on the species. These are all common and widespread bacteria. For instance, Enterococcus spp. and related species are common, commensal members of gut communities in mammals and birds and also opportunistic pathogens (Byappanahalli et al. 2012).

The observed low overlapping of barn swallow CMs is consistent with the hypothesis that environmental features of the areas where individuals live are the main drivers of avian microbiota diversification and that CMs may therefore largely differ among geographical populations of the same species (Lucas \& Heeb 2005; Waite \& Taylor 2015). This confirms the importance of studies describing the microbiota of different and distant geographical populations of the same species. In addition, the investigation of the ecological and evolutionary consequences of such inter-population differences is a promising research avenue.

The CM of one adult female barn swallow (\#F1) was dominated by bacteria of the orders Chlamydiales (86\%) and Lactobacillales (13\%). Despite the large abundance of bacteria that are potential pathogens for vertebrates and a CM structure different from that of the other individuals, this female was recaptured in the colony during the year after the sampling (R. Ambrosini personal observation) and thus survived to the following breeding season. We can hypothesize that the prevalence of Chlamydiales in the distal part of the gut may have a less detrimental effect on bird survival than in other parts of the digestive trait, or that these bacteria are less detrimental to birds than to other vertebrates. This observation also confirms previous reports that gut microbiota of migratory passerines can include potentially pathogenic species without apparent effect on bird fitness (Lewis et al. 2016).

Most of the 2482 OTUs found in the CM of barn swallows had a low prevalence. Indeed, $25 \%$ of OTUs was found in only one individual, $27 \%$ in more than half of the individuals, and only $4 \%$ in all the birds. The prevalence of rare OTUs and the large inter-individual variation in $\mathrm{CM}$ structure is consistent with the findings of previous investigations of the gut bacterial communities of birds (e.g. Lucas \& Heeb 2005; Hird et al. 2014; Lewis et al. 2016) and of other vertebrate taxa (Burr et al. 2005; Lucas \& Heeb 2005; Ley et al. 2008; White et al. 2010). We did not observe significant differences between the sexes in the CM structure, consistently with a previous investigation on the barn swallow in the Czech Republic. This may result from the horizontal transfer of bacteria among adults due to within-pair and extra-pair copulations (Kreisinger et al. 2015). We also did not observe a statistically significant difference in alpha or beta diversity between fledglings and adults. Our findings therefore contrast with the results of Kreisinger et al. (2017), who observed a higher alpha diversity of CM of adults than of nestlings and hypothesized that this was due to the ongoing formation of gut bacterial assemblage in nestlings.

Admittedly, the lack of significant differences in the structure of CMs among age and sex classes may be due to the small number of CMs considered in the present study. Indeed, our results show that males, females and fledglings form rather separate clusters, and future investigations on a larger sample may disclose differences in CM structures that were not revealed in the present study. Alternatively, it may be explained by the fact that, in birds, exogenous and environmental factors seem to influence the composition of the CM (Lucas \& Heeb 2005; Waite \& Taylor 2014) more than endogenous ones, and that barn swallows breeding in the same colony are exposed to the same environmental conditions, including availability of insect prey. In addition, we 
sampled juveniles at a later age than Kreisinger et al. (2017), i.e. when they had already fledged and may have had time to acquire a CM more similar to that of adults. Finally, transfer of bacteria may occur not only among adults (see above), but also between adults and nestlings. Indeed, parents may transfer bacteria to nestlings when feeding them, but they can also acquire bacteria from them, e.g. when removing faecal sacs (Turner 2006).

This first description of the CM of barn swallows in northern Italy and the third ever performed on this species (Kreisinger et al. 2015, 2017), although based on a rather small sample, thus suggests that CMs of geographically different barn swallow populations seem dominated by bacteria belonging to the same phyla, while differences can be observed in the dominant genera.

\section{ACKNOWLEDGEMENTS}

We warmly thank Piero Paloschi and the staff of the Cascina Sora riding school for allowing us to study barn swallows in their stables and Valentina Bertolini, Margherita Corti and Luca Ambrosini for assistance during field work. We also thank Prof. Riccardo Borgoni for advices on statistical analyses and Dr Alice Squassina and COPAN ITALIA SPA for providing swabs for sampling. COPAN ITALIA SPA had no role in designing experiments or in data analysis. We thank Javier Balbontin and two anonymous referees for constructive comments on an earlier version of the manuscript.

\section{DISCLOSURE STATEMENT}

No potential conflict of interest was reported by the authors.

\section{FUNDING}

This work was supported by the University of Milano Bicocca [grant number 2014-ATE-0437].

ORCID

Federica Musitelli (D) http://orcid.org/0000-0003-1109-5087

Roberto Ambrosini (iD http://orcid.org/0000-0002-7148-1468

Diego Rubolini (D) http://orcid.org/0000-0003-2703-5783

Nicola Saino (D) http://orcid.org/0000-0002-0230-3967

Andrea Franzetti (D) http://orcid.org/0000-0003-1279-9940

\section{SUPPLEMENTAL MATERIAL} 1388294

Supplemental data for this article can be accessed at https://doi.org/10.1080/03949370.2017. 


\section{REFERENCES}

Benjamini Y, Yekutieli D. 2001. The control of the false discovery rate in multiple testing under dependency. Ann Stat. 29:1165-1188.

Bik EM, Costello EK, Switzer AD, Callahan BJ, Holmes SP, Wells RS, Carlin KP, Jensen ED, Venn-Watson S, Relman DA. 2016. Marine mammals harbor unique microbiotas shaped by and yet distinct from the sea. Nat Commun. 7:10516.

Brown JW. 2014. Principles of microbial diversity. Washington (DC): ASM Press.

Burr G, Gatlin D III, Ricke S. 2005. Microbial ecology of the gastrointestinal tract of fish and the potential application of prebiotics and probiotics in finfish aquaculture. J World Aquac Soc. 36:425-436.

Byappanahalli MN, Nevers MB, Korajkic A, Staley ZR, Harwood VJ. 2012. Enterococci in the environment. Microbiol Mol Biol Rev. 76:685-705.

Chao A, Shen TJ. 2003. Nonparametric estimation of Shannon's index of diversity when there are unseen species in sample. Environ Ecol Stat. 10:429-443.

Colston TJ, Jackson CR. 2016. Microbiome evolution along divergent branches of the vertebrate tree of life: what is known and unknown. Mol Ecol. 25:3776-3800.

De Cáceres M, Legendre P, Moretti M. 2010. Improving indicator species analysis by combining groups of sites. Oikos. 119:1674-1684.

Edgar RC. 2013. UPARSE: highly accurate OTU sequences from microbial amplicon reads. Nat Methods. 10:996-998.

Filippidou S, Jaussi M, Junier T, Wunderlin T, Jeanneret N, Regenspurg S, Li P-E, Lo C-C, Johnson S, McMurry K, et al. 2015. Genome sequence of Aeribacillus pallidus Strain GS3372, an endospore-forming bacterium isolated in a deep geothermal reservoir. Genome Announc. 3:e00981-15.

Fraune S, Bosch TCG. 2010. Why bacteria matter in animal development and evolution. Bioessays. 32:571-580.

Gandolfi I, Canedoli C, Imperato V, Tagliaferri I, Gkorezis P, Vangronsveld J, Padoa Schioppa E, Papacchini M, Bestetti G, Franzetti A. 2017. Diversity and hydrocarbondegrading potential of epiphytic microbial communities on Platanus $x$ acerifolia leaves in an urban area. Environ Pollut. 220:650-658.

Godoy-Vitorino F, Goldfarb KC, Karaoz U, Leal S, Garcia-Amado MA, Hugenholtz P, Tringe SG, Brodie EL, Dominguez-Bello MG. 2012. Comparative analyses of foregut and hindgut bacterial communities in hoatzins and cows. ISME J. 6:531-541.

Hird SM, Carstens BC, Cardiff SW, Dittmann DL, Brumfield RT. 2014. Sampling locality is more detectable than taxonomy or ecology in the gut microbiota of the brood-parasitic Brown-headed Cowbird (Molothrus ater). PeerJ. 2:e321.

Huber JA, Mark Welch D, Morrison HG, Huse SM, Neal PR, Butterfield DA, Sogin ML. 2007. Microbial population structures in the deep marine biosphere. Science. 318:97-100.

Kokko H, Ranta E, Ruxton G, Lundberg P, Dudash M. 2002. Sexually transmitted disease and the evolution of mating systems. Evolution. 56:1091-1100.

Kreisinger J, Č́ížková D, Kropáčková L, Albrecht T. 2015. Cloacal microbiome structure in a long-distance migratory bird assessed using deep 16sRNA pyrosequencing. PLoS ONE. 10: e0137401.

Kreisinger J, Kropáčková L, Petrželková A, Adámková M, Tomášek O, Martin J-F, Michálková R, Albrecht T. 2017. Temporal stability and the effect of transgenerational transfer on fecal microbiota structure in a long distance migratory bird. Front Microbiol. 8:50.

Legendre P, Legendre L. 2012. Numerical ecology, 3rd ed. Amsterdam: Elsevier Science B.V.

Lewis WB, Moore FR, Wang S. 2016. Characterization of the gut microbiota of migratory passerines during stopover along the northern coast of the Gulf of Mexico. J Avian Biol. 47:659-668. 
Ley RE, Hamady M, Lozupone C, Turnbaugh PJ, Ramey RR, Bircher JS, Schlegel ML, Tucker TA, Schrenzel MD, Knight R. 2008. Evolution of mammals and their gut microbes. Science. 320:1647-1651.

Lombardo MP. 1998. On the evolution of sexually transmitted diseases in birds. J Avian Biol. 29:314-321.

Lucas FS, Heeb P. 2005. Environmental factors shape cloacal bacterial assemblages in great tit Parus major and blue tit P. caeruleus nestlings. J Avian Biol. 36:510-516.

Mead GC. 1997. Bacteria in the gastrointestinal tract of birds. In: Mackie RI, et al., editors. Gastrointestinal microbiology. Vol. 2: gastrointestinal microbes and host interactions. New York: Chapman and Hall; p. 216-240.

Møller AP. 1994. Sexual selection and the barn swallow. Oxford: Oxford University Press.

Muegge BD, Kuczynski J, Knights D, Clemente JC, González A, Fontana L, Henrissat B, Knight R, Gordon JI. 2011. Diet drives convergence in gut microbiome functions across mammalian phylogeny and within humans. Science. 332:970-974.

Sharon G, Segal D, Ringo JM, Hefetz A, Zilber-Rosenberg I, Rosenberg E. 2010. Commensal bacteria play a role in mating preference of Drosophila melanogaster. Proc Natl Acad Sci. 107:20051-20056.

Sheldon BC. 1993. Sexually transmitted disease in birds: occurrence and evolutionary significance. Philos Trans R Soc Lond B. 339:491-497.

Turner A. 2006. The barn swallow. London: T \& A D Poyser.

Van Dongen WFD, White J, Brandl HB, Moodley Y, Merkling T, Leclaire S, Blanchard P, Danchin E, Hatch SA, Wagner RH. 2013. Age-related differences in the cloacal microbiota of a wild bird species. BMC Ecol. 13:11.

Waite DW, Deines P, Taylor MW. 2012. Gut microbiome of the critically endangered New Zealand parrot, the kakapo (Strigops habroptilus). PLoS ONE. 7:e35803.

Waite DW, Taylor MW. 2014. Characterizing the avian gut microbiota: membership, driving influences, and potential function. Front Microbiol. 5:1-12.

Waite DW, Taylor MW. 2015. Exploring the avian gut microbiota: current trends and future directions. Front Microbiol. 6:1-12.

Wang Q, Garrity GM, Tiedje JM, Cole JR. 2007. Naive Bayesian classifier for rapid assignment of rRNA sequences into the new bacterial taxonomy. Appl Environ Microbiol. 73:5261-5267.

Wang Y, Qian P-Y. 2009. Conservative fragments in bacterial 16S rRNA genes and primer design for $16 \mathrm{~S}$ ribosomal DNA amplicons in metagenomic studies. PLoS ONE. 4:e7401.

White J, Mirleau P, Danchin E, Mulard H, Hatch SA, Heeb P, Wagner RH. 2010. Sexually transmitted bacteria affect female cloacal assemblages in a wild bird. Ecol Lett. 13:1515-1524. 